\title{
Seasonal Fluctuations in Birth Weight and Neonatal Limb Length; Does Prenatal Vitamin D Influence Neonatal Size and Shape?
}

\section{Citation}

McGrath, John J., Douglas Keeping, Sukanta Saha, David C. Chant, Daniel E. Lieberman, and Michael J. O'Callaghan. 2005. Seasonal fluctuations in birth weight and neonatal limb length; Does prenatal vitamin D influence neonatal size and shape? Early Human Development 81(7): 609-618.

\section{Published Version}

doi:10.1016/j.earlhumdev.2005.03.013

\section{Permanent link}

http://nrs.harvard.edu/urn-3:HUL.InstRepos:3743677

\section{Terms of Use}

This article was downloaded from Harvard University's DASH repository, and is made available under the terms and conditions applicable to Other Posted Material, as set forth at http:// nrs.harvard.edu/urn-3:HUL.InstRepos:dash.current.terms-of-use\#LAA

\section{Share Your Story}

The Harvard community has made this article openly available.

Please share how this access benefits you. Submit a story.

Accessibility 


\title{
Seasonal fluctuations in birth weight and neonatal limb length; does prenatal vitamin $D$ influence neonatal size and shape?
}

\author{
John J. McGrath ${ }^{\mathrm{a}, \mathrm{b}, *}$, Douglas Keeping ${ }^{\mathrm{c}}$, Sukanta Saha ${ }^{\mathrm{a}}$, David C. Chant ${ }^{\mathrm{a}}$, \\ Daniel E. Lieberman ${ }^{\mathrm{d}}$, Michael J. O'Callaghan ${ }^{\mathrm{e}}$
}

\author{
${ }^{a}$ Queensland Centre for Mental Health Research, The Park Centre for Mental Health, \\ Wacol, QLD 4076, Australia \\ ${ }^{\mathrm{b}}$ Department of Psychiatry, University of Queensland, St Lucia, QLD 4065, Australia \\ 'Queensland Fertility Group, 225 Wickham Terrace Brisbane QLD 4000, Australia \\ ${ }^{\mathrm{d}}$ Department of Anthropology, Harvard University, 11 Divinity Avenue, Cambridge, MA 02138, USA \\ ${ }^{e}$ Child Development and Rehabilitation Services, University of Queensland, \\ Mater Misericordiae Hospital, Raymond Terrace, South Brisbane, QLD 4101, Australia
}

Accepted 23 March 2005

\section{KEYWORDS \\ Seasons; \\ Birth weight; \\ Limb length; \\ Anthropometry; \\ Vitamin D}

\begin{abstract}
Background: Birth weight is known to fluctuate with season of birth, however, there is little information about seasonal variation in neonatal anthropometric measures. Aims: The aim of this study was to examine seasonal fluctuations in birth weight and selected anthropometric measures.

Study design and subjects: The birth weight of singletons born after at least 37 weeks gestation was extracted from a perinatal register in south-east Queensland $(n=350,171)$. Mean monthly birth weights for this period were examined. Based on a separate birth cohort, principal component analysis was undertaken on neonatal anthropometric measures $(n=1233)$. Seasonality was assessed by (a) spectral analysis of time series data, (b) monthly and seasonal comparison of outcomes.

Results: Based on register data, birth weight displayed clear annual periodicity. Birth weight differed significantly when compared by month and season. Infants born in October were the heaviest (3484 g), while May-born infants were the lightest (3459 g; $P=0.001)$. Based on the cohort anthropometric data, three components were identified related to (a) overall size, (b) limb length, and (c) head size and skin-fold
\end{abstract}

\footnotetext{
* Corresponding author. Queensland Centre for Mental Health Research, The Park Centre for Mental Health, Wacol, QLD 4076, Australia. Tel.: +61 732718694; fax: +61 732718698 .

E-mail address: john_mcgrath@qcsr.uq.edu.au (J.J. McGrath).
} 
thickness. Each of these components displayed significant seasonal variation. In particular, prominent seasonal fluctuations in limb length were identified, with peak limb length associated with winter/spring birth.

Conclusion: Environmental factors that have regular seasonal fluctuation influence both the size and shape of neonates. Animal experiments suggest that prenatal hypovitaminosis D may underlie greater limb length. Because birth weight and limb length are associated with a broad range of important health outcomes, the seasonal exposures underlying these effects warrant further scrutiny from a public health perspective.

(C) 2005 Elsevier Ireland Ltd. All rights reserved.

\section{Introduction}

Birth weight has long been acknowledged as an important measure of neonatal health [1]. In addition to providing insights into prenatal development, this variable is known to be associated with a wide range of important cognitive, behavioural and health outcomes in infancy, childhood and adulthood. For example, even within the normal range of birth weights, heavier birth weight has been associated with superior neurocognitive outcomes in several cohort studies [2-6]. There is accumulating evidence linking birth weight and wide range of chronic, adult-onset disorders $[7,8]$.

In addition to birth weight, features of body shape at birth have been explored in order to determine if certain neonatal phenotypes are (a) associated with particular types of prenatal exposures [9] and (b) with particular types of adult disorders [10]. The mechanisms of action underlying shape at birth are far from resolved $[11,12]$. However, there is agreement that we need to generate candidate exposures that contribute to neonatal shape and size and explore research designs that may help fractionate factors influencing developmental pathways [13].

Clearly, body shape and birth weight are influenced by a complex matrix of genetic and epigenetic factors operating on the maternalfetal unit. Twin studies are one type of 'natural experiment' that allows us to tease apart genetic and environmental components contributing to variations in neonatal measures [14]. Season of birth studies are another type of natural experiment that can help generate candidate environmental factors. Certain exposures tend to fluctuate in a regular fashion within the year, while, at the group level, other environmental and genetic factors remained relatively stable. Thus, if seasonal fluctuations are linked to an outcome, then they can help generate new candidate exposures.

Most, but not all, studies of season of birth and birth weight have reported that winter and spring births tend to be slightly heavier and slightly longer compared to summer and autumn births. For example, Selvin and Janerich [15] examined birth weight in a sample of 1,524,229 infants born in New York State exclusive of New York City. They found that babies born in summer months (June, July and August) had the lowest birth weights in the year while those born in March, April and May (Spring) had the highest birth weight.

Roberts [16] reported on a general sample of 43,141 births in Hong Kong (latitude 22.2 N), there was a significant within-year fluctuation, with peak birth weight in March (early spring) and a nadir in August (late summer). Matsuda and colleagues [17] examined seasonal fluctuation in birth weight in a large sample of singletons from Japan $(n=16,796,415)$. Significant annual periodicity was identified, with peak birth weight found in May (spring). In a large Danish study $(n=1,166,206)$, annual fluctuations in both birth weight and birth length were confirmed [18], with peak birth length found in April (spring).

Based on the Dunedin birth cohort (latitude 45.5S), Waldie and colleagues [19] reported annual periodicity in both birth weight and birth length with peak values for both measures occurring in the southern Hemisphere winter and spring. In a sample from Northern Ireland [20], significant seasonal fluctuations in birth weight were found in singletons born after at least 36 weeks of gestation $(n=418,817)$. The lowest birth weights were found in July (summer) and highest in February (winter). Not all studies have found a seasonal fluctuation in birth weight [21], and some studies have reported paradoxical increased weight in the summer born [22].

We had the opportunity to explore seasonal influences on neonatal anthropometric measures in south east Queensland, a subtropical region in the southern Hemisphere. Based on the literature, we predicted that babies born in winter and spring (i.e., June to November) would be significantly heavier than babies born in summer and autumn (December to May). In addition, we predicted 
that those babies born in winter and spring would be longer compared to summer/autumn born infants.

\section{Methods}

The data in this paper were drawn from two discrete data sets. Seasonal fluctuations in birth weight were examined in the Queensland Perinatal Register, which includes all births in public and private hospitals in south-east Queensland, Australia (latitude approximately $27 \mathrm{~S}$ ). Data were available for a 13-year period (January 1987 to December 1999). The analyses were restricted to singleton pregnancies with a gestation of at least 37 weeks. The assessment for seasonal fluctuations in birth weight involved (a) spectral analyses (using SAS Proc Spectra) to assess periodicity in the full time series (in particular, we were interested if there was a regular twelve month pattern to any variations over time), (b) visual presentation of the mean monthly values, and (c) comparisons by monthly, seasonal (spring=September, October, November; Summer = December, January, February etc.), and half-yearly (winter/spring versus summer/autumn) comparisons.

The detailed anthropometric data were drawn from a birth cohort (Mater University Study of Pregnancy; MUSP), the details of which are described elsewhere $[23,24]$. During the period June
1982 to September 1983, additional detailed anthropometric measures were collected on a subset $(n=1240)$ of the 2568 infants recruited into the main study. Compared to the neonates who did not get anthropometric assessment, the infants included in this study did not differ on sex or birth weight (data not shown), however, infants in the anthropometric study had slightly longer gestations. The mean (and standard deviation) for gestation for the included neonates was 39.9 (1.1) weeks versus 39.8 (1.1) weeks for the other cohort members $(t=-2.76, d f=6938, p<0.01)$.

The anthropometric measurements included birth weight (in grams), and various distance and circumference measures (in millimeters), including two measures related to head size and shape (head circumference, maximum biparietal distance), neck-rump length, shoulder and hip width, limb segment circumference (taken at mid-length on the left side) measurements of the upper and lower segments of the arm and leg (left side), chest and abdominal circumference. Skin fold thickness was also assessed (in millimeters) for four regions (subscapular, abdominal, triceps, and anterior thigh). All anthropometric measures were taken by one trained nurse following a predefined research protocol. Test-retest reliability for the anthropometric measures was reported as being acceptable (least precision for lower limb circumference, subscapular and triceps skin fold measurements) [25].

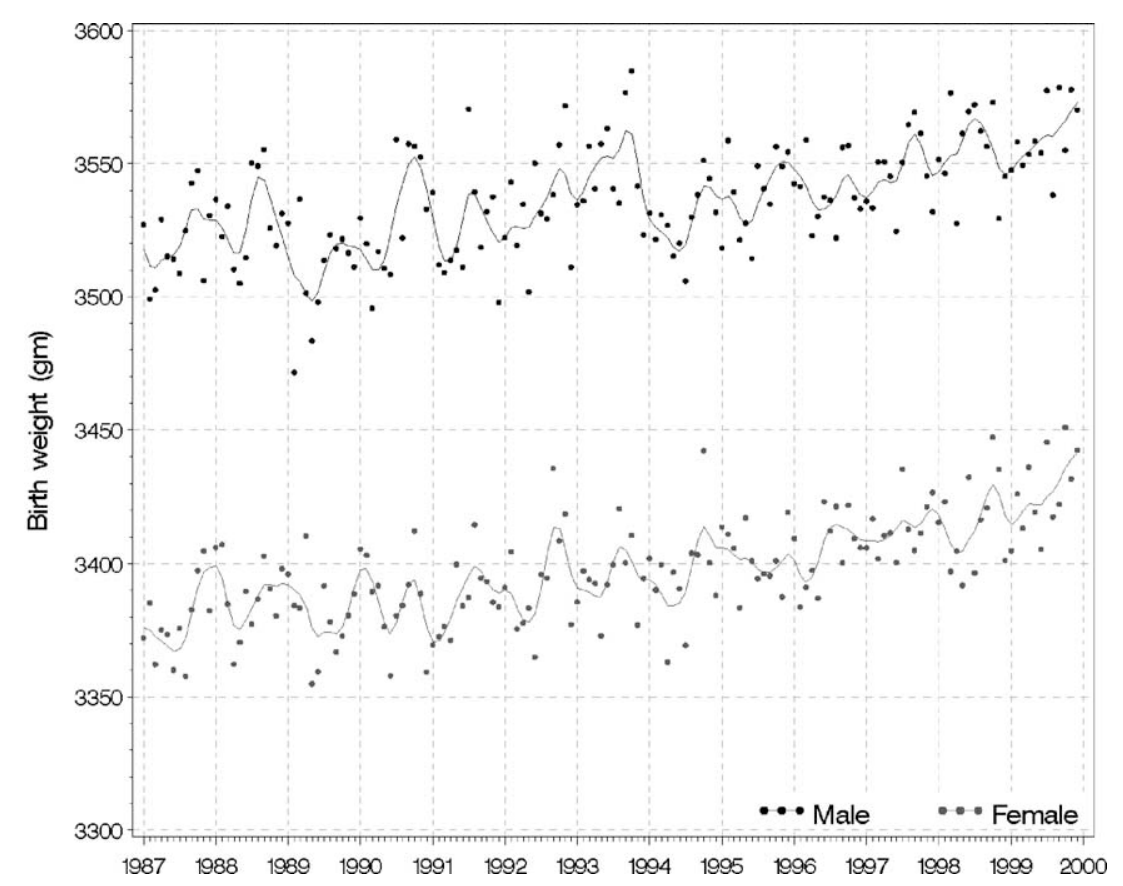

Figure 1 Time series of mean monthly birth weight, by sex (males are heavier), for singleton pregnancy of at least 37 weeks $($ male $=179,899$, female $=170,272)$, with a smoothing spline superimposed. 
In order to summarize the birth anthropometric variables in an unbiased fashion, we used principal component analysis [9]. This method identifies components which are derived weighted averages of the entered variables that explain as much of the between-subject variation as is possible. The components were compared according to month, season and half-year with Proc GLM (a general linear model suitable for group comparisons) and Tukey post-hoc tests, and overall mean monthly values for the components and the key variables loading on these components, were inspected for males and females separately [26].

\section{Results}

Based on singleton pregnancy of at least 37 weeks gestation in the Perinatal register, data were available on 350,171 births. Fig. 1 shows the
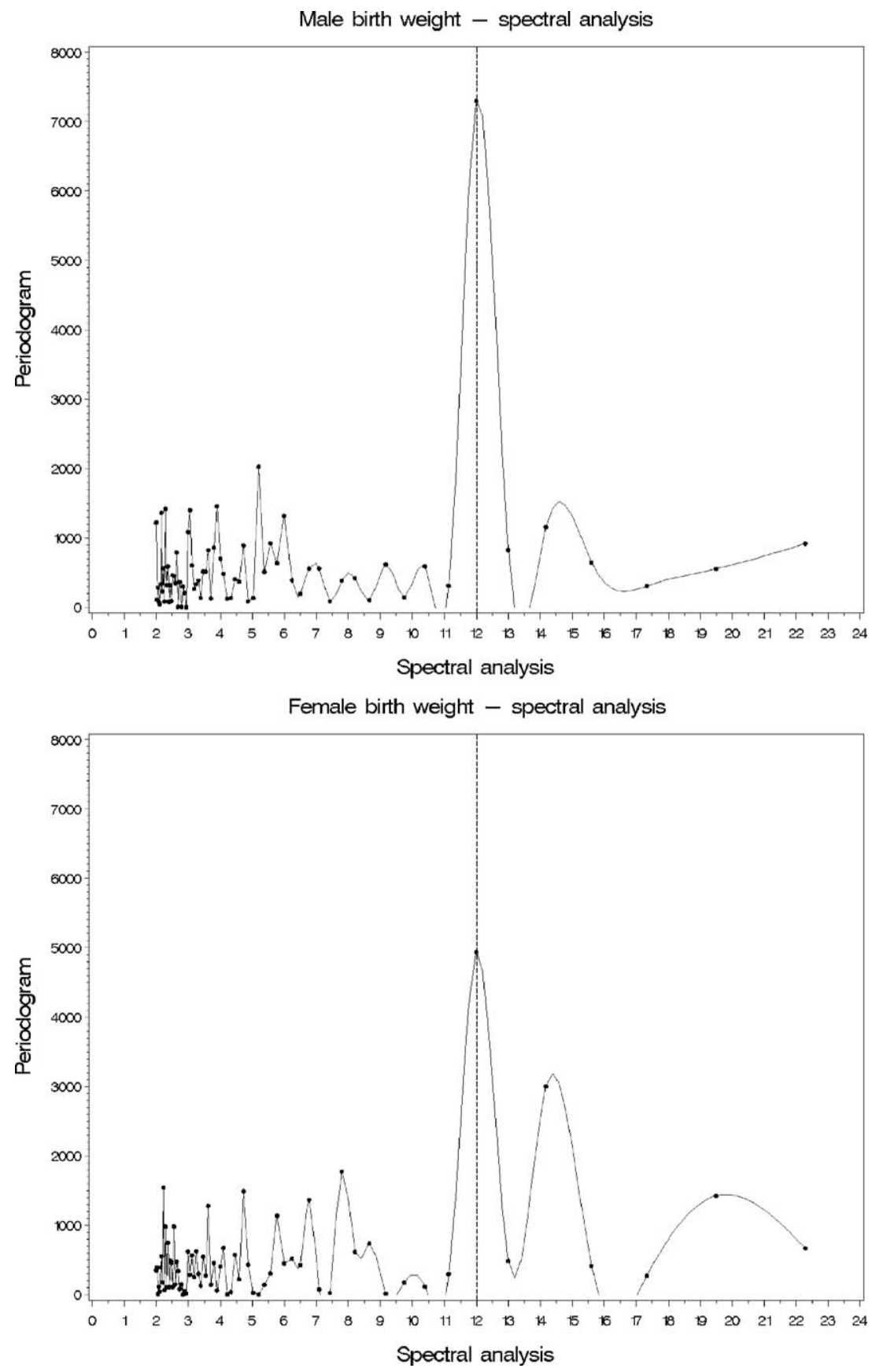

Figure 2 Spectral analysis of mean monthly birth weigh for males (upper panel) and females (lower panel). The vertical reference bar is shown at 12 months. 
monthly mean for birth weight for males and females separately. Apart from the within-year seasonal fluctuations, the figure also shows a secular increase in mean monthly birth weight over the 13-year epoch. Spectral analysis confirmed the most prominent periodicity for both males and females occurred at exactly 12 months, however, this effect was more pronounced for males (Fig. 2).

Fig. 3 shows the overall mean monthly birth weight for persons. Mean monthly birth weights was significantly different when compared by month $(F=2.37, d f=11, p=0.01$; heaviest in October at $3484 \mathrm{~g}$, lightest in May at $3459 \mathrm{~g}$ ), and by season ( $F=6.55, d f=3, p=0.001)$. When controlling for sex and gestation, winter/spring births were significantly heavier compared to summer/autumn births $(F=48.07, d f=1,350,090, p<0.001)$. Using half-yearly comparisons, the difference in birth weight was $13 \mathrm{~g}$ for males (winter/spring mean $=3544 \mathrm{~g}$, summer $/$ autumn $=3531 \mathrm{~g}$ ), and $7 \mathrm{~g}$ for females (winter/spring mean $=3401 \mathrm{~g}$, summer / autumn $=3394 \mathrm{~g}$ ).

Based on the cohort with anthropometric measures, principal component analyses identified 3 main components. The variable loadings on these components are shown in Table 1. The first component loads positively for birth weight and all measures and represents a general size component ("size factor"). The second component has positive loadings on upper arm, lower arm, thigh and lower leg, and negative loadings on hip width and the four skin-fold measures ("limb length factor"). The third component has positive loading
Table 1 Principal component analyses for birth weight and other anthropometric measures $(n=1233)$

\begin{tabular}{llrr}
\hline Measurement & Factor 1 & Factor 2 & Factor 3 \\
\hline Birth weight (g) & 0.93 & -0.04 & -0.15 \\
Head circumference & 0.71 & 0.00 & -0.40 \\
Biparietal diameter & 0.56 & -0.14 & -0.53 \\
Neck-rump length & 0.55 & 0.00 & -0.33 \\
Shoulders width & 0.70 & -0.23 & -0.29 \\
Hips width & 0.61 & -0.35 & -0.29 \\
Upper arm length & 0.56 & 0.64 & 0.03 \\
Upper arm circumference & 0.85 & -0.03 & 0.06 \\
Lower arm length & 0.42 & 0.77 & 0.15 \\
Lower arm circumference & 0.88 & -0.06 & 0.04 \\
Chest circumference & 0.82 & 0.01 & -0.08 \\
Abdomen circumference & 0.82 & 0.09 & 0.04 \\
Thigh length & 0.53 & 0.64 & 0.00 \\
Thigh circumference & 0.81 & -0.16 & 0.03 \\
Lower leg length & 0.39 & 0.77 & 0.12 \\
Lower leg circumference & 0.81 & -0.09 & 0.05 \\
Skin-fold subscapular & 0.66 & -0.33 & 0.46 \\
Skin-fold abdominal & 0.62 & 0.02 & 0.48 \\
Skin-fold triceps & 0.53 & -0.42 & 0.41 \\
Skin-fold anterior thigh & 0.66 & -0.46 & 0.32 \\
Variance explained & $9.55 \%$ & $2.75 \%$ & $1.51 \%$ \\
\hline
\end{tabular}

Factor 1 is a general size factor. Factor 2 includes limb length and skin-fold thickness. Factor 3 includes head size and reduced skin fold measures.

for the four skin-fold measures and negative loading on the head measures (head circumference and biparietal diameter). This factor, labelled "head size and skin-fold thickness factor," may identify the relationship between less body fat associated with preserved head size. The mean monthly distribution of the three components is shown in Fig. 4. Each of the three factors was

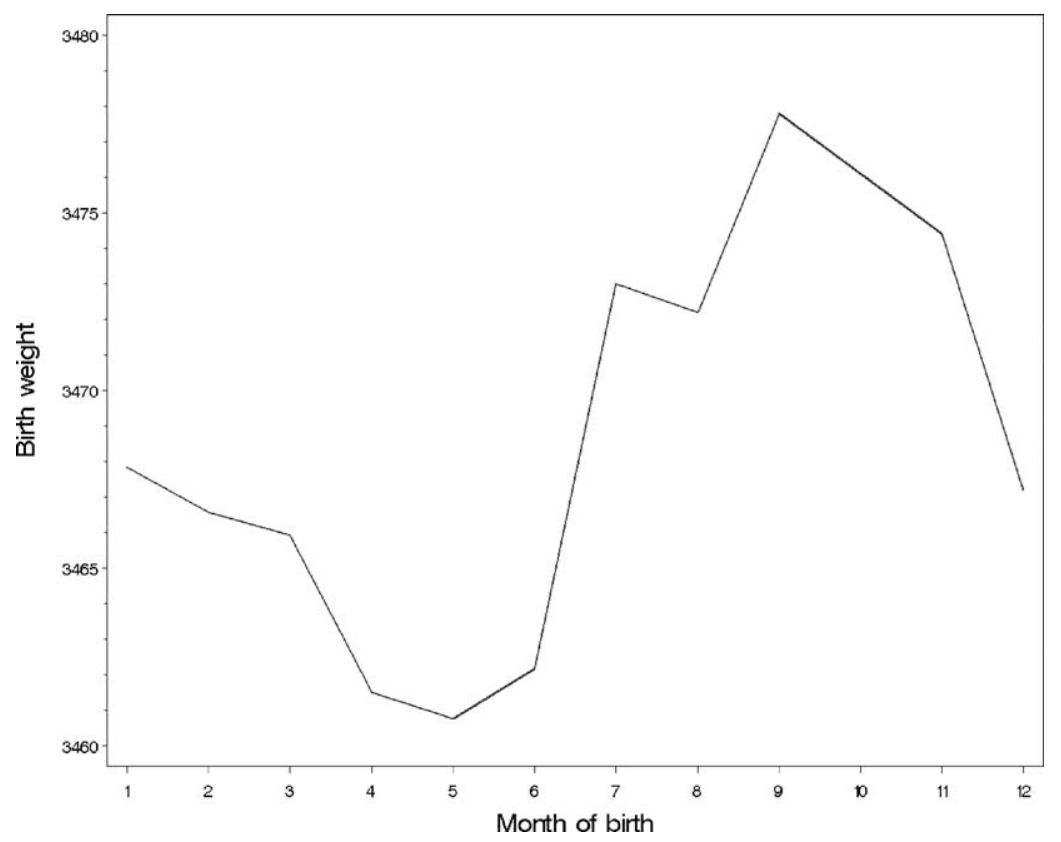

Figure 3 Overall mean monthly birth weight in grams for persons $(n=350,171)$. 


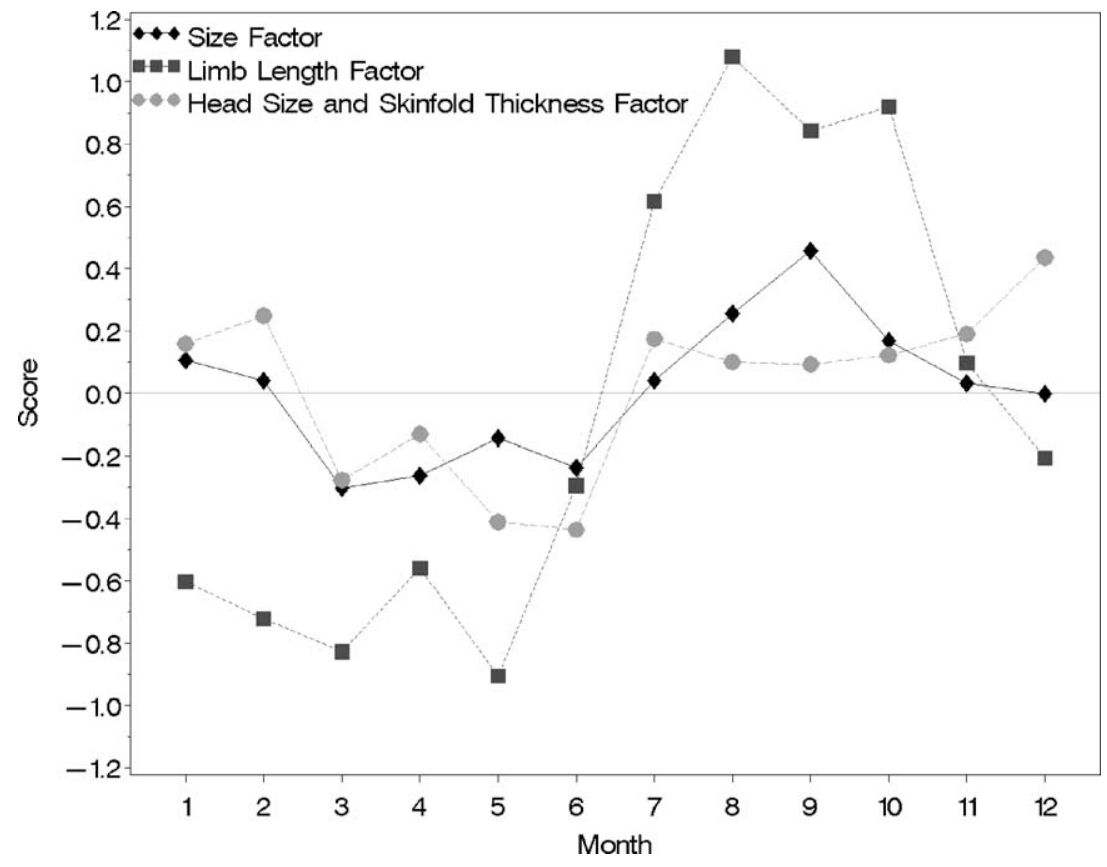

Figure 4 Overall mean monthly scores for the three principal components.
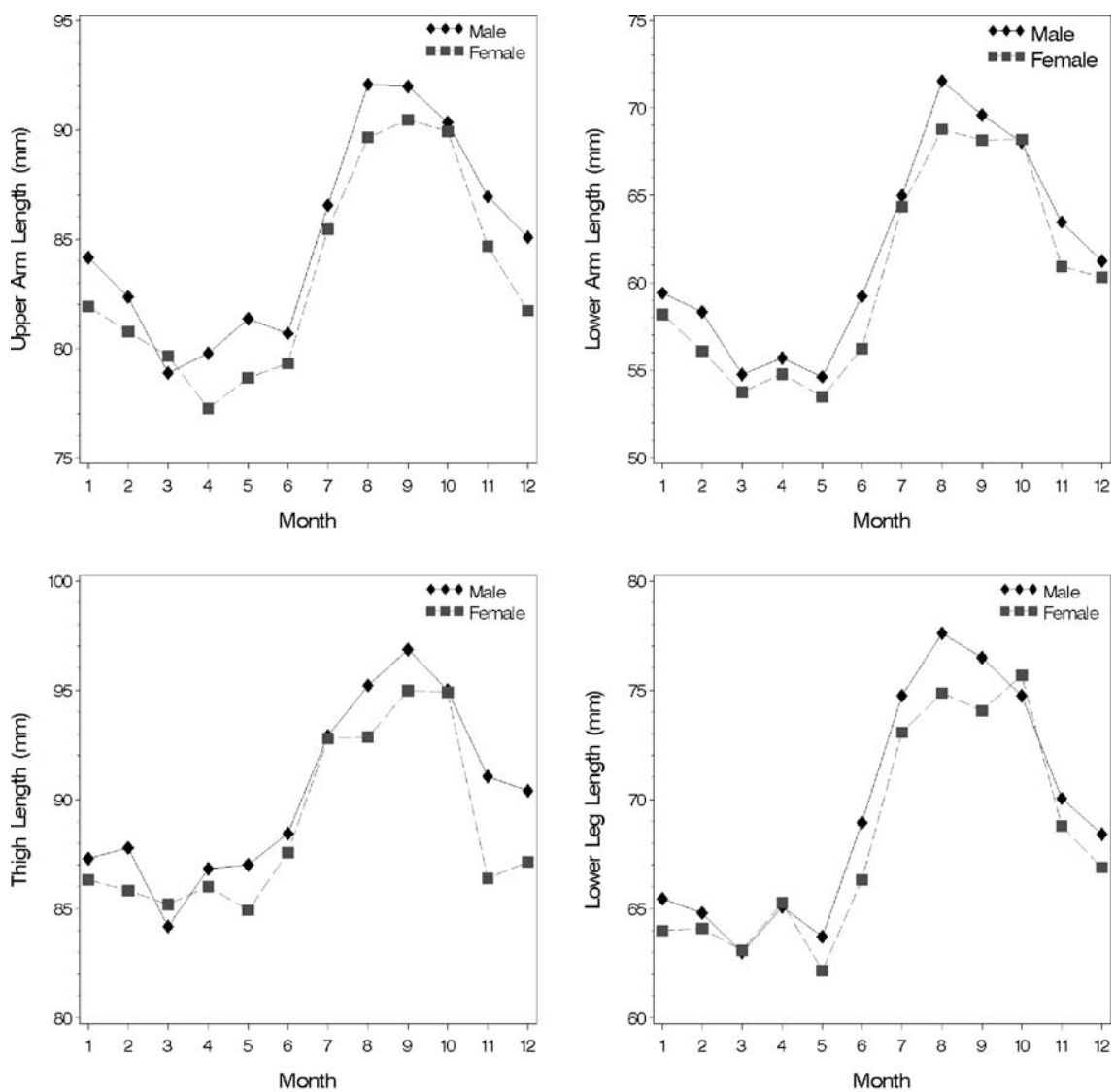

Figure 5 Mean monthly values for limb length for males and females separately. The upper panel shows the withinyear variation for upper arm length (left panel) and lower arm length (right panel). The lower panel shows the withinyear distribution for thigh length (left panel) and lower leg length (right panel). 
significantly different when compared by month and season (data not shown). The size and limb length factors (but not the Head size and skin-fold thickness factor) also differed significantly on the winter/spring versus summer/autumn comparison (data not shown). Remarkably, the mean monthly values for each of the four limb measured displayed a clear sine wave fluctuation for both males and females (Fig. 5).

\section{Discussion}

There are regular seasonal fluctuations in both the size and shape of babies born in south-east Queensland. Winter and spring born infants are slightly heavier compared to summer and autumn born infants (25-g difference between neonates born in October versus May). This effect had a strong 12month periodicity. The findings are consistent with the seasonal fluctuation in birth length described by others [18], but extend these results by showing subtle differences in the shape of the infants. In addition to being heavier, infants born in winter and spring in this study were found to have disproportionately longer arms and longer legs (but not longer trunks) compared to those born in summer and autumn.

The principal component analysis identified three patterns of shape and size, and each of these were found to have monthly or seasonal variation. The second factor (limb length factor, which explained $2.75 \%$ of the variance) had the most prominent seasonal fluctuations. Compared to summer and autumn born infants, winter and spring born infants are more 'gracile,' with longer arms and longer legs, narrower hips and reduced skinfold measurements (suggestive of lower body fat). This seasonal change in the shape of the neonates is in addition to the seasonal change in size-indeed birth weight had a very small negative loading on the second factor $(-0.04)$. The third factor identified an association between larger head size and reduced skin-fold measures, perhaps relating to 'head sparing' association with suboptimal fetal nutrition [12].

The register-based study also confirmed a secular trend for heavier birth weight over time, as found in many studies $[18,27]$. Curiously, the amplitude and shape of the within-year fluctuation show intradecadal variation. South-east Queensland has substantial intradecadal climate fluctuations due to the southern oscillation index (El Nino) [28]. Thus regardless of the biological mechanisms underlying the findings of this study, the findings suggest that large-scale climate factors influence the dose and timing of the regular, within-year seasonally fluctuating exposure.

\section{The search for candidate risk-modifying variables}

The challenge for researchers involved in seasonality research is to sift through the highly intercorrelated maze of variables that have regular, within-year variation. Ultimately, most of these variables are down-stream consequences of biometeorological variables such as temperature, rainfall and ultraviolet radiation. These variables (cold, heat stress, dehydration, thermoregulation) can impact directly on health status [29-31]. Winter is associated with lower levels of ultraviolet radiation, which is strongly associated with low levels of vitamin D [32]. Like most animals, humans have various biorhythms (mainly circadian and monthly rather than circannual) [33]. Photoperiod is associated with diurnal fluctuations in various hormones and melatonin [34]. Indirectly, seasonal fluctuations can impact on health status via nutrition (e.g., availability of seasonal food products like fruit), energy expenditure (e.g., work load varies across seasons in agrarian societies), and disease exposures (e.g., respiratory viruses may be more prevalent in winter, vectors for malaria have seasonal breeding cycles) [35]. In addition to this complex web of environmental changes, human behaviour is modified in a transactional fashion with the environment. For example, in cold seasons, we tend to remain indoors, use internal heating and wear more clothing. Thus, seasonal changes in weather can result in a complex but inter-correlated matrix of exposures. The task for the researcher is to generate biologically-plausible candidate risk-modifying factors (e.g., exactly which nutritional or infective factor might be implicated), rather than examine proxy markers of exposures (e.g., month of year, temperature etc.).

\section{Does prenatal vitamin $D$ alter fetal development?}

What seasonally fluctuating candidate exposures could result in not only changes in the weight of neonates, but also the length of their limbs? Murray and colleagues have argued that exposure to cold temperatures during mid-gestation reduce placental blood flow, and thus results in the lower birth weights associated with late spring and in summer 
[20]. One might predict that small within-year fluctuations in maternal diet or energy expenditure could result in alterations in birth weight, but it is less clear how this might explain the change in limb length. Future studies should examine seasonal fluctuations in maternal weight gain in order to explore these factors. There is also evidence suggesting that the maternal environment may influence the 'programming' of the fetal suprachiasmatic nucleus, which is involved in the generation of circadian rhythms [36,37]. Because of the links between melatonin, growth hormone and bone remodelling [38], these mechanisms require further scrutiny.

Recent animal experiments have shown that low prenatal vitamin D influences fetal growth. For example, compared to control animals, the new born offspring of normocalcaemic rats deprived of vitamin D were significantly heavier and have subtle changes in the shape of the brain [39]. Of particular relevance to the association between winter and spring birth and longer limbs, recent studies in the guinea pig have linked low prenatal vitamin D and growth plate hypertrophy [40]. This experiment found expansion of the hypertrophic chondrocyte area and an increase in the osteoid surface and thickness in the growth plates of fetuses from vitamin $D$ deplete (but normocalcaemic) guinea pigs. The absence of vitamin $D$ leads to unchecked proliferation of the chrondrocytes, which can then perturb the orderly trajectory of skeletal growth. These changes occur in the absence of rickets. Mindful that long bones determine limb length and that each long bone has two growth plates (proximal and distal), we speculate that the striking seasonal pattern of limb length reflects the influence of fluctuating vitamin $D$ levels across the year on growth plate width. In particular, this mechanism may differentially impact on leg height rather than trunk height, as the thigh and lower leg include four, large growth plates.

The vitamin $D_{3}$ system is unique in the sense that its production depends primarily on the action of sunlight on the skin [41]. Ultraviolet $B$ radiation acts on a cholesterol metabolite in the epidermis to produce previtamin D. Hydroxylation in the liver (to calcidiol) and then in the kidney creates the active moiety, 1,25-dihydroxyvitamin $D_{3}$ (calcitriol), which is a seco-steroid hormone. Vitamin D production is strongly and consistently associated with the duration of the photoperiod, which in turn is influenced by latitude and season [32,42]. A study undertaken in south-east Queensland (the site of the current study) found levels of 25 hydroxyvitamin $D_{3}$ had significant seasonal fluctuations (lowest in winter/spring) and that $23.4 \%$ have insufficient and $8 \%$ have deficient levels of 25 hydroxyvitamin $\mathrm{D}_{3}$ (defined as less than 50 and $38.5 \mathrm{nmol} /$ I respectively) [43]. Of particular relevance to this paper, fetal vitamin $D$ requirements increase during pregnancy (related to the increased need for fetal calcium), thus maternal vitamin D levels tend to fall during the third trimester, especially if this occurs during winter [44].

Vitamin D operates predominantly via a nuclear receptor (the vitamin D receptor, VDR). The VDR is the smallest member the phylogenetically-conserved superfamily of nuclear receptors that includes receptors for ligands such as retinoic acid, glucocorticoids, thyroid hormone and the sex hormones [45]. Vitamin D has been shown to induce the transcription of a large number of target genes [46]. Of particular relevance to the potential for vitamin $\mathrm{D}$ to modulate development, there are several levels of interaction between vitamin $D$ and other known morphogens. For example, the VDR regulates transcription by forming heterodimers with other nuclear hormone receptors, most principally with the retinoid $X$ receptor (RXR), whose cognate ligand is 11-trans retinol, a vitamin A derivative [47]. VDR and the thyroid hormone receptor (TXR) compete for RXR such that formation of the TXR-RXR heterodimer represses gene transcription by VDR by sequestering RXR [48]. Based on its effects on many different cell types, it is now known that vitamin $D$ has potent antiproliferative properties. The presence of vitamin D dampens proliferation and induces cells to exit the cell cycle via differentiation and, in certain circumstances, induces apoptosis $[49,50]$.

\section{Implications for population health}

While the effects at the individual level are very small, at a population level, the seasonally fluctuating exposures responsible for changes in neonatal size and shape have important implications for health and development. As detailed above, heavier birth weights are associated with increased intelligence [2]. While the current study cannot comment on whether or not the seasonal changes in size and shape persist into adult, other studies have reported an association between season of birth and adult height $[19,51]$. While there is evidence that increased adult height is associated with a decreased risk of cardiorespiratory disease [52], the health outcomes are not always beneficial. For example, taller individuals have an increased risk of cancer $(20-60 \%$ increased risk for a range of cancers) [53]. Many studies have shown that it is leg 
length rather than truncal height that acts as a 'biomarker' of risk [54].

This study reports, for the first time, that limb length is influenced by exposures that have regular, seasonal fluctuations. Regardless of the nature of the risk factors that underlie this finding, the fact that shape and size has seasonal fluctuations in this sample invites researchers to generate candidate exposures for further analytic epidemiological studies. In particular, we propose that low prenatal vitamin $D$ is a plausible candidate exposure. Future studies should examine the association between maternal vitamin $D$ status and infant shape and size, and, by extension, if low prenatal vitamin $D$ also influences adult health status [55].

\section{Acknowledgements}

JM received support from a Queensland Smithsonian Fellowship. The authors are grateful to Sue Cornes for providing the perinatal register data; Ruth Morley for comments on an earlier draft; and to the investigators of the Mater University Study of Pregnancy.

\section{References}

[1] Kramer MS. Determinants of low birth weight: methodological assessment and meta-analysis. Bull World Health Organ 1987;65(5):663-737.

[2] Matte TD, Bresnahan M, Begg MD, Susser E. Influence of variation in birth weight within normal range and within sibships on IQ at age 7 years: cohort study. BMJ 2001; 323(7308):310-3114.

[3] Jefferis BJ, Power C, Hertzman C. Birth weight, childhood socioeconomic environment, and cognitive development in the 1958 British birth cohort study. BMJ 2002;325(7359):305.

[4] Richards M, Hardy R, Kuh D, Wadsworth ME. Birth weight and cognitive function in the British 1946 birth cohort: longitudinal population based study. BMJ 2001;322(7280): 199- 203.

[5] Shenkin SD, Starr JM, Pattie A, Rush MA, Whalley LJ, Deary IJ. Birth weight and cognitive function at age 11 years: the Scottish Mental Survey 1932. Arch Dis Child 2001;85(3): $189-96$.

[6] Sorensen HT, Sabroe S, Olsen J, Rothman KJ, Gillman MW, Fischer P. Birth weight and cognitive function in young adult life: historical cohort study. BMJ 1997;315(7105):401- 3.

[7] Susser E, Matte TD. Early antecedents of adult health. J Urban Health 1998;75(2):236-41.

[8] Barker DJ. Mothers, babies and health in later life. Edinburgh: Churchill Livingstone; 1998.

[9] Hindmarsh PC, Geary MP, Rodeck CH, Kingdom JC, Cole TJ. Intrauterine growth and its relationship to size and shape at birth. Pediatr Res 2002;52(2):263-8.

[10] Barker DJ, Osmond C, Simmonds SJ, Wield GA. The relation of small head circumference and thinness at birth to death from cardiovascular disease in adult life. BMJ 1993; 306(6875):422- 6 .
[11] Kramer MS, Olivier M, McLean FH, Dougherty GE, Willis DM, Usher RH. Determinants of fetal growth and body proportionality. Pediatrics 1990;86(1):18- 26.

[12] Kramer MS, McLean FH, Olivier M, Willis DM, Usher RH. Body proportionality and head and length 'sparing' in growthretarded neonates: a critical reappraisal. Pediatrics 1989; 84(4):717- 23.

[13] Sacks DA. Determinants of fetal growth. Curr Diabetes Rep 2004;4(4):281 - 7.

[14] Morley R, Dwyer T, Carlin JB. Studies of twins: can they shed light on the fetal origins of adult disease hypothesis? Twin Res 2003;6(6):520-5.

[15] Selvin S, Janerich DT. Four factors influencing birth weight. Br J Prev Soc Med 1971;25(1):12-6.

[16] Roberts DF. Environment and the fetus. In: Roberts DF, Thomson AM, editors. The biology of human fetal growth. London: Taylor and Francis; 1975.

[17] Matsuda S, Sone T, Doi T, Kahyo H. Seasonality of mean birth weight and mean gestational period in Japan. Hum Biol 1993;65(3):481 - 501.

[18] Wohlfahrt J, Melbye M, Christens P, Andersen AM, Hjalgrim $H$. Secular and seasonal variation of length and weight at birth. Lancet 1998;352(9145):1990.

[19] Waldie KE, Poulton R, Kirk IJ, Silva PA. The effects of preand post-natal sunlight exposure on human growth: evidence from the southern Hemisphere. Early Hum Dev 2000; 60(1):35- 42 .

[20] Murray LJ, O'Reilly DP, Betts N, Patterson CC, Davey Smith $A E$, Evans $A E$. Season and outdoor ambient temperature: effects on birth weight. Obstet Gynaecol 2000;96(5 Pt. 1): 689-95.

[21] Phillips DI, Young JB. Birth weight, climate at birth and the risk of obesity in adult life. Int J Obes Relat Metab Disord 2000;24(3):281 - 7

[22] Gloria-Bottini F, Meloni GF, Finocchi A, Porcu S, Amante A, Bottini E. Rh system and intrauterine growth. Interaction with season of birth. Dis Markers 2000;16(3-4): $139-42$.

[23] Keeping JD, Najman JM, Morrison J, Western JS, Andersen MJ, Williams GM. A prospective longitudinal study of social, psychological and obstetric factors in pregnancy: response rates and demographic characteristics of the 8556 respondents. Br J Obstet Gynaecol 1989;96(3):289-97.

[24] O'Callaghan FV, O'Callaghan M, Najman JM, Williams GM, Bor W. Maternal alcohol consumption during pregnancy and physical outcomes up to 5 years of age: a longitudinal study. Early Hum Dev 2003;71(2):137-48.

[25] Keeping JD. Determinants and components of size at birth [MD thesis]. University of Queensland; 1981.

[26] SAS Institute W. SAS 8.02. Cary, NC; 2001.

[27] Kramer MS, Morin I, Yang H, Platt RW, Usher R, McNamara $\mathrm{H}$, et al. Why are babies getting bigger? Temporal trends in fetal growth and its determinants. J Pediatr 2002;141(4): $538-42$.

[28] Done SJ, Holbrook NJ, Beggs PJ. The quasi-biennial oscillation and Ross river virus incidence in Queensland, Australia. Int J Biometeorol 2002;46(4):202 - 7.

[29] Mercer JB. Cold-an underrated risk factor for health. Environ Res 2003;92(1):8-13.

[30] McGeehin MA, Mirabelli M. The potential impacts of climate variability and change on temperature-related morbidity and mortality in the United States. Environ Health Perspect 2001;109(Suppl. 2):185-9.

[31] Naughton MP, Henderson A, Mirabelli MC, Kaiser R, Wilhelm JL, Kieszak SM, et al. Heat-related mortality during a 1999 heat wave in Chicago. Am J Prev Med 2002; 22(4):221- 7 . 
[32] Holick MF. Environmental factors that influence the cutaneous production of vitamin D. Am J Clin Nutr 1995; 61(3 Suppl.):638S-45S.

[33] Wehr TA. A 'clock for all seasons' in the human brain. Prog Brain Res 1996;111:321- 42.

[34] Wehr TA. Effect of seasonal changes in daylength on human neuroendocrine function. Horm Res 1998;49(3-4):118-24.

[35] McMichael AJ. Human frontiers, environments and disease. . Cambridge: Cambridge University Press; 2001.

[36] Kennaway DJ, Flanagan DE, Moore VM, Cockington RA, Robinson JS, Phillips DI. The impact of fetal size and length of gestation on 6-sulphatoxymelatonin excretion in adult life. J Pineal Res 2001;30(3):188-92.

[37] Kennaway DJ. Programming of the fetal suprachiasmatic nucleus and subsequent adult rhythmicity. Trends Endocrinol Metab 2002;13(9):398-402.

[38] Cardinali DP, Ladizesky MG, Boggio V, Cutrera RA, Mautalen C. Melatonin effects on bone: experimental facts and clinical perspectives. J Pineal Res 2003;34(2):81-7.

[39] Eyles D, Brown J, Mackay-Sim A, McGrath J, Feron F. Vitamin D3 and brain development. Neuroscience 2003; 118(3):641-53.

[40] Rummens K, van Bree R, Van Herck E, Zaman Z, Bouillon $F A$, Van Assche FA, et al. Vitamin D deficiency in guinea pigs: exacerbation of bone phenotype during pregnancy and disturbed fetal mineralization, with recovery by $1,25(\mathrm{OH}) 2 \mathrm{D} 3$ infusion or dietary calcium-phosphate supplementation. Calcif Tissue Int 2002;71(4):364-75.

[41] DeLuca HF, Zierold C. Mechanisms and functions of vitamin D. Nutr Rev 1998;56(2 Pt 2):S4 [discussion S54-75].

[42] Webb AR, Kline L, Holick MF. Influence of season and latitude on the cutaneous synthesis of vitamin D3: exposure to winter sunlight in Boston and Edmonton will not promote vitamin D3 synthesis in human skin. J Clin Endocrinol Metab 1988;67(2):373-8.

[43] McGrath JJ, Kimlin MG, Saha S, Eyles DW, Parisi AV. Vitamin D insufficiency in south-east Queensland. Med J Aust 2001; 174(3):150-1.

[44] MacLennan WJ, Hamilton JC, Darmady JM. The effects of season and stage of pregnancy on plasma 25-hydroxy- vitamin D concentrations in pregnant women. Postgrad Med J 1980;56(652):75- 9

[45] Lander ES, Linton LM, Birren B, Nusbaum C, Zody MC, Baldwin $\mathrm{J}$, et al. Initial sequencing and analysis of the human genome. Nature 2001;409(6822):860-921.

[46] Darwish H, DeLuca HF. Vitamin D-regulated gene expression. Crit Rev Eukaryot Gene Expr 1993;3(2):89-116.

[47] Prufer K, Barsony J. Retinoid X receptor dominates the nuclear import and export of the unliganded vitamin $D$ receptor. Mol Endocrinol 2002;16(8):1738-51.

[48] Raval-Pandya M, Freedman LP, Li H, Christakos S. Thyroid hormone receptor does not heterodimerize with the vitamin $D$ receptor but represses vitamin $D$ receptormediated transactivation. Mol Endocrinol 1998;12(9): 1367-79.

[49] DeLuca HF, Krisinger J, Darwish H. The vitamin D system: 1990. Kidney Int Suppl 1990;29:S2-8.

[50] Johnson CS, Hershberger PA, Bernardi RJ, McGuire TF, Trump DL. Vitamin D receptor: a potential target for intervention. Urology 2002;60(3 Suppl. 1):123-30 [discussion 30-1].

[51] Weber GW, Prossinger $\mathrm{H}$, Seidler $\mathrm{H}$. Height depends on month of birth. Nature 1998;391(6669):754-5.

[52] Davey Smith G, Hart C, Upton M, Hole D, Gillis C, Watt G, et al. Height and risk of death among men and women: aetiological implications of associations with cardiorespiratory disease and cancer mortality. J Epidemiol Community Health 2000;54(2):97-103.

[53] Gunnell D, Okasha M, Smith GD, Oliver SE, Sandhu J, Holly $J M$. Height, leg length, and cancer risk: a systematic review. Epidemiol Rev 2001;23(2):313-42.

[54] Gunnell D. Can adult anthropometry be used as a 'biomarker' for prenatal and childhood exposures? Int J Epidemiol 2002;31(2):390-4.

[55] McGrath J. Does 'imprinting' with low prenatal vitamin D contribute to the risk of various adult disorders? Med Hypotheses 2001;56(3):367-71. 